\title{
Influence of Head and Neck Muscle Contraction on Tinnitus
}

\author{
Sang Hoon Kim, Tae Hyun Kim, Chul Won Yang, Sun A Choi, \\ Seung Geun Yeo, Jae Yong Byun and Moon Suh Park \\ Department of Otolaryngology, School of Medicine, Kyung Hee University, Seoul, Korea
}

\section{두경부 근육 수축이 이명의 발현에 미치는 영향}

김상훈 - 김태현 · 양철원 · 최선아 · 여승근 · 변재용 - 박문서

경희대학교 의과대학 이비인후-두경부외과학교실

Received August 14, 2013

Revised October 2, 2013

Accepted October 15, 2013

Address for correspondence

Moon Suh Park, MD, PhD

Department of Otolaryngology,

School of Medicine,

Kyung Hee University,

892 Dongnam-ro, Gangdong-gu,

Seoul 134-727, Korea

Tel $+82-2-440-6237$

Fax $+82-2-440-6296$

E-mail pmsuh@yahoo.co.kr
Background and Objectives Tinnitus can be classified into two types, otogenic and somatic tinnitus. Somatic tinnitus can occur even when the ear is normal, as it is known that tinnitus can occur after there is movement in the muscles of the head and neck. This study aims to characterize tinnitus and clarify the nature of tinnitus when it occurs from the contraction of the head and neck muscle.

Subjects and Method Thirty-five people with normal hearing, who had no history of otitis media or inner ear disease, were taken as subjects. First, we investigated whether the natural tinnitus occurred or not in the silent environment and checked its characteristics for five minutes. We then implemented eight different kinds of muscle contractions maneuver and measured whether the tinnitus occurred and the recorded the onset time, duration and location of the occurrence of the tinnitus.

Results Among the total of 35 subjects inspected, 15 (42.9\%) people felt the natural tinnitus. In terms of natural tinnitus, ringing was the most common characteristic and heard most often from both sides. Twenty (57.1\%) subjects out of total 35 subjects inspected felt tinnitus after the contraction of the head and neck muscles. Tinnitus after the resistance to a force applied by the people to the occiput was the most common for $14(40.0 \%)$ people, followed by parietal and right temporal area. The most common location was the left side for $6(17.1 \%)$ subjects followed by right side and both sides. For the type of tinnitus after the contraction of muscles, ringing was observed the most by $6(17.1 \%)$ subjects, followed by high frequency and pulsatile sound. The average onset time of the tinnitus was 8.8 seconds and the average duration was 29.6 seconds. Conclusion The study showed that the muscle contraction of head and neck affects the occurrence of tinnitus for people who had no tinnitus. By clarifying the occurrence of tinnitus due to the contraction of muscles, the study identified the basic features of hearing and the role of the somatic tinnitus. Korean J Otorhinolaryngol-Head Neck Surg 2014;57:84-8

Key Words Muscle contraction · Tinnitus.

\author{
서 론 \\ 이명은 외부 음원의 자극과 관계없이 귀 혹은 다른 부위에 \\ 서 소리가 들린다고 호소하는 증상이다. 많은 연구에도 불구 \\ 하고 이명의 병태생리는 복잡하고 아직 밝혀지지 않은 부분
}

이 많아 치료에 어려움이 크다. 이명은 귀 외에 신경계, 대사의 이상이나 혈관, 근골격계의 이상에서도 발생할 수 있으며 원 인이 하나 이상인 경우도 흔하다. ${ }^{1)}$ 이명은 소리의 음원 유무 나 원인에 따라 보통 객관적과 주관적 혹은 중추성과 말초성 이명으로 분류할 수 있는데, 이명의 정의에 있어 그 범위를 규 
정하는 것은 이명의 성질과 원인을 연구하는 데 중요한 지표 가 된다.

체성소리(somatosound)는 $\mathrm{Anon}^{2)}$ 이 처음 정의한 이래 객관 적 이명으로 분류되기도 하지만 경우에 따라서는 객관적 이명 으로 분류할 수 없는 여러 근육, 혈관 기원의 소리를 규정하 는 데 사용되었다.

이명이 없는 정상인에서 두부나 목의 근육을 수축함으로 써 이명을 발생할 수 있다는 사실은 경험적으로 일부 알려져 있었으나 이명 환자에서 두경부의 근육들을 움직이면 이명의 성질에 변화를 가져올 수 있음이 실제로 규명되기 시작한 것은 그리 오래되지 않았다. ${ }^{3-5)}$ 최근에는 이러한 이명을 배측와우신 경핵(dorsal cochlear nucleus)의 탈억제 때문에 생기는 체성감 각-청각의 상호작용(somatosensory-auditory interaction) 으로 설명하려는 시도가 늘어나고 있어, ${ }^{4}$ 앞으로 이명의 분류, 병리 규명 및 치료에 있어 새로운 계기를 마련하고 있다. 즉 이 명은 이성(otogenic)과 체성으로 나뉠 수 있고, 체성 이명은 청 각 기능이 정상이며 청신경이나 내이, 중이 질환등이 없을 때 도 생길 수 있으며 악관절 장애나 목뼈 손상과 같은 영역에 이 상이 있을 때 역시 나타날 수 있다.)

상기한 사실에서 두경부 근육를 수축하여 인위적으로 발생 할 수 있는 이명의 특성에 관한 연구가 이명의 원인을 규명하 고 이명 치료에 있어 의미가 있을 것이라 생각하여 본 연구를 계획하였다.

\section{대상 및 방법}

2010년 1월부터 2010년 10월까지 중이염이나 내이 질환의 병 력이 없는 건강한 성인 중, 이학적 소견상 고막이 정상이고 현 재 이명이 없으며, 순음청력검사상 $250 \mathrm{~Hz}$ 에서 $8000 \mathrm{~Hz}$ 사 이에서 $20 \mathrm{~dB}$ 이하의 청력 역치를 보이면서, 고실도 검사에 서 양측 $\mathrm{A}$ 형을 나타낸 35 명을 대상으로 하였다. 연구 대상자 는 연구 시행에 대한 동의서를 작성하였으며 본 연구는 헬싱 키 선언을 준수하였다. 순음청력기기는 ORBITER 922 Version 2(Madsen, Denmark)를 사용하였고, 고실도 검사 기기는 GSI TYMPSTAR V2(Grason-Stadler, Eden Prairie, MN, USA)
를 사용하였다.

우선 방음실에서 5 분간 편안한 자세로 앉아 자연적으로 발 생하는 이명 여부를 알아보았다. 그 후 두경부 근육의 수축과 관련된 8가지 술식(maneuver)을 시행했는데, 이것은 Levine 의 술식을 참고로 저자들이 변형하여 만든 것이다(Table 1). 각 술식을 시행하는 과정에서, 두께 $10 \mathrm{~cm}$ 의 고정된 폴리에 틸렌 재질의 판을 피검사자의 후두부, 전두부, 두정부, 하악 골부, 양측 측두부 각각의 정중앙에 고정시킨 이후, 피검사자 가 이 판의 직각 방향으로 힘을 주어 근수축이 나타나게 하였 다. 그리고 머리를 좌우로 돌리면서 근수축을 발생시키는 경 우에는 폴리에틸렌 판을 피검사자의 광대 부위(zygoma)에 고 정시켜 힘을 주어 고개를 돌리도록 하였다.

이와 같은 8가지 술식은 모두 머리를 중앙에 위치한 상태 에서 각각 10 초간 시행되었으며, 이후 이명의 발생 여부, 종류 및 그 발생 시기와 지속기간, 발생 위치를 측정했다. 각 근육 수축 사이의 시간은 각각 5 분 이상의 충분한 시간이 지난 이 후 시행되어 이전 근수축의 영향이 없도록 하였다. 그리고 자 연 발생하는 이명이 있을 경우에도 동일한 측정을 시행하였 다. 만약 자연 발생한 이명이 두경부 근육의 수축 시작 후에 도 느껴진다면, 그 소리는 무시하도록 지시하였다. 단 이명의 종류는 같으나, 발생 위치의 변화 및 소리의 강도가 현저하게 증가한 것으로 느낀 경우에는 근육 수축 이후 이명을 느낀 것 으로 간주하였다.

\section{결 과}

전체 피검자 35 명의 평균 연령은 $30.2 \pm 6.4$ 세이며, 남녀 구 성은 각각 남자 15 명, 여자 20명이었다. 이들 중 15 명인 $42.9 \%$ 가 방음실에서 일정시간 경과 후, 자연적으로 발생하는 이명 을 느꼈다. 남녀별로 자연 이명을 느낀 비율은 남자의 $40 \%$ 인 6 명, 여자의 $45 \%$ 인 9명이 이명을 느꼈으며, 여성에서 더 높은 비율을 보였다. 자연 이명의 종류는 울리는 소리 6 명, 높은 소리 4명, 낮은 소리 3 명 순이었고, 위치는 양측에서 들리는 경우가 5 명으로 가장 많았으며, 좌측과 우측의 빈도는 동일 한 것으로 나타났다.

Table 1. Eight voluntary muscle contraction maneuvers of the head and neck

\begin{tabular}{ll}
\hline 1 & Head in neutral position, resistance to a force applied by the patient to the occiput \\
2 & Head in neutral position, resistance to a force applied by the patient to the forehead \\
3 & Head in neutral position, resistance to a force applied by the patient to the vertex \\
4 & Head in neutral position, resistance to a force applied by the patient to the mandible upward \\
5 & Head in neutral position, resistance to a force applied by the patient to the right temporal bone \\
6 & Head in neutral position, resistance to a force applied by the patient to the left temporal bone \\
7 & Head turned to the right, resistance to a force applied by the patient to the right zygoma \\
8 & Head turned to the left, resistance to a force applied by the patient to the left zygoma \\
\hline
\end{tabular}


두경부 근육 수축 후, 전체 피검자 35명 중 20명(57.1\%)에 서 이명이 감지되었다. 여성에서 $60.0 \%$, 남성에서 $53.3 \%$ 가 근 육 수축 이후 이명이 발생하였으며, 자연 이명에서와 마찬가 지로 여성에서 높은 비율을 나타냈다. 근수축 전 이명을 느꼈 던 환자 15 명 중 12 명이 수축 이후에 이명을 느꼈으며, 근수축 전 조용한 환경에서 자연 이명이 없었던 8명의 환자에서 수축

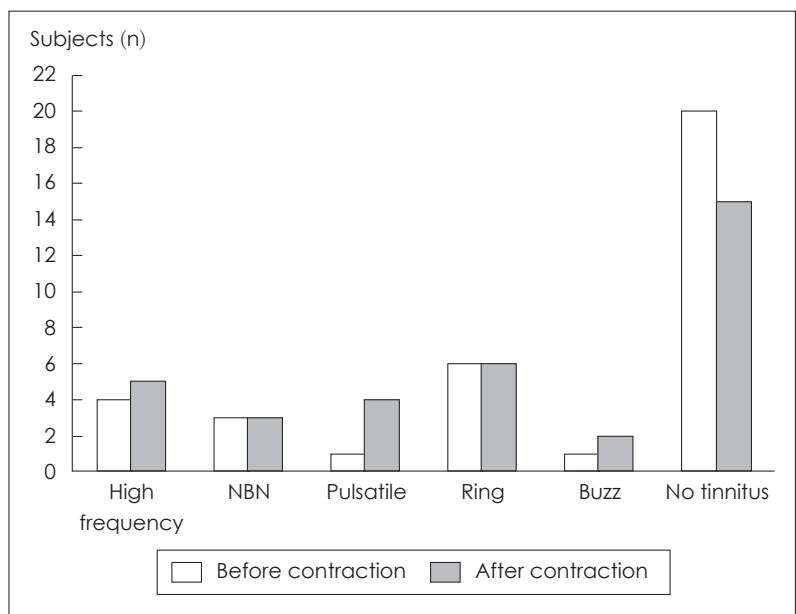

Fig. 1. Characteristics of tinnitus. NBN: narrow band noise.

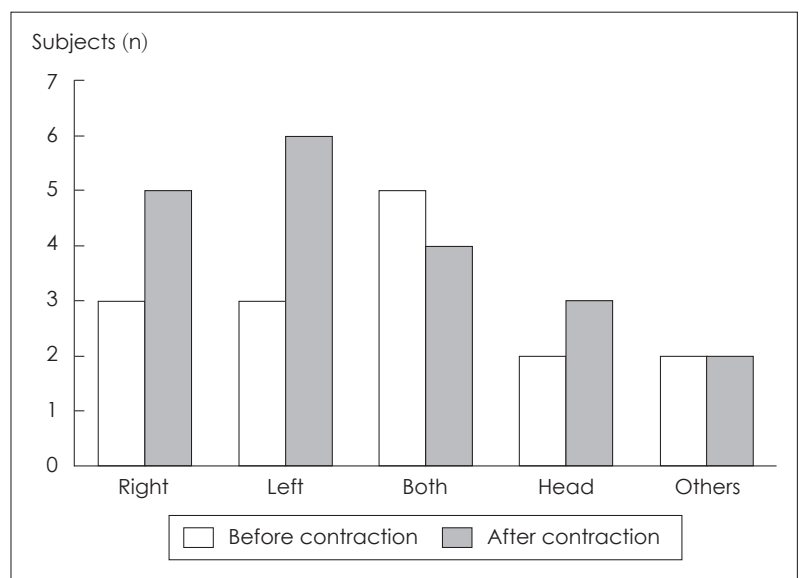

Fig. 2. Location of tinnitus.

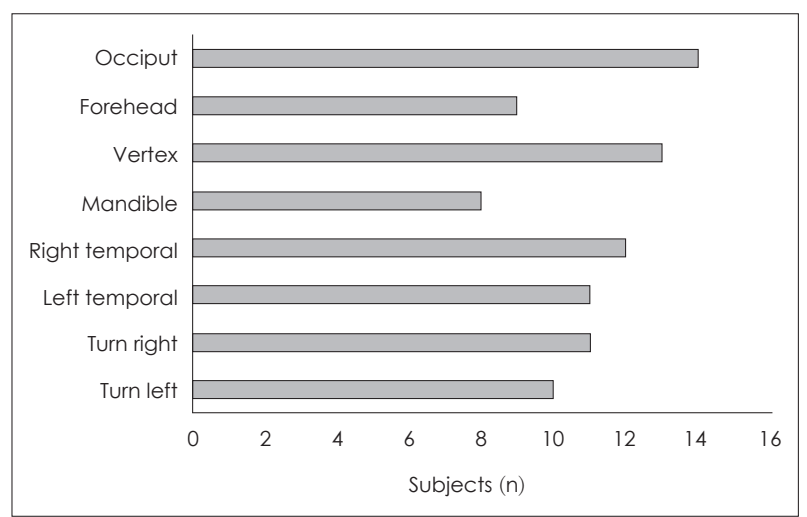

Fig. 3. Tinnitus awareness after contraction.
이후, 이명이 발생한 것으로 나타났다.

이명의 종류는 울리는 소리가 6명으로 가장 많았으며, 높은 소리, 맥동성 소리 순이었다(Fig. 1). 수축 후 생긴 이명의 위치 는 좌측 귀 6명, 우측 귀 5명, 양측 귀 4명 순이었다(Fig. 2). 이 명은 근육 수축 후 평균 14.8초가 지난 후 들리기 시작했고, 평균 지속 기간은 29.6초였다. 근육 수축 이후, 이명의 발생 빈 도는 후두부 압박 때 14 명으로 가장 많았으며, 다음으로 두 정부 13 명, 우측 측두부 12 명 순으로 나타났다(Fig. 3).

고개를 우측으로 돌린 후 가장 빠른 시간 내에 이명이 들 리기 시작하였으며, 다음이 고개를 좌측으로 돌렸을 때 순이 었다(Fig. 4). 따라서 고개를 돌리는 근육의 움직임에서 이명 의 발생이 빠르게 나타나는 것을 확인할 수 있었다. 이명은 평 균적으로 고개를 오른쪽으로 돌렸을 때 34.1초로 가장 오래 지 속되었고, 다음이 우측 측두부, 좌측 측두부 순이었다(Fig. 5).

\section{고 찰}

이명은 신체의 특정 음원에서 발생하는 객관적 이명과 그 음원이 확실하지 않은 주관적 이명으로 분류하기도 하지만 이 음향방사에 의한 이명을 감안한다면 이 분류는 엄밀하게는

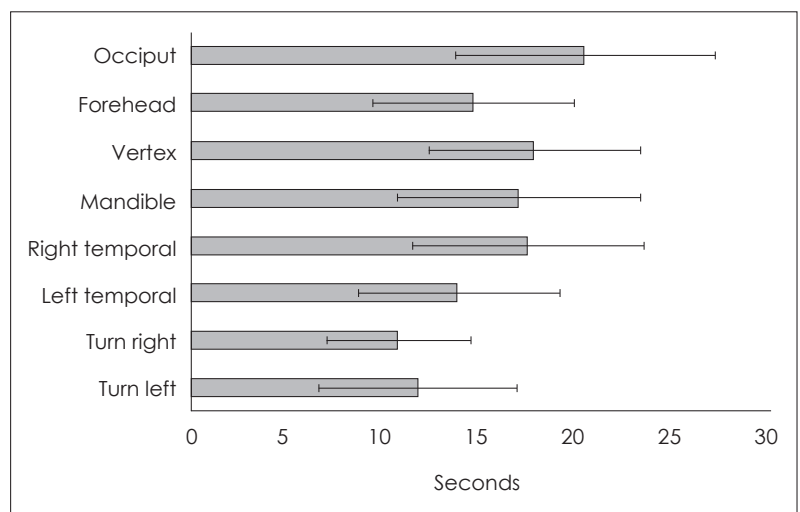

Fig. 4. Mean onset time (mean \pm standard deviation) of tinnitus.

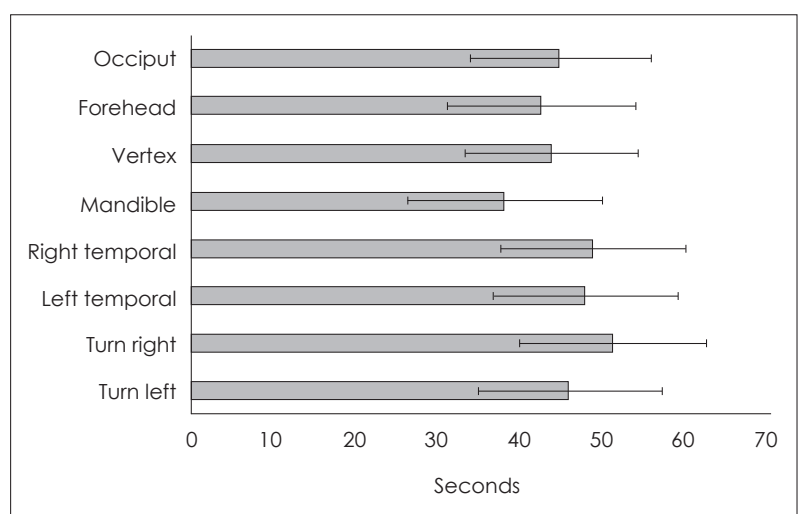

Fig. 5. Mean duration (mean \pm standard deviation) of tinnitus. 
측정기기의 감도에 따른 것이라 할 수 있다. 이명은 귀 자체의 원인 외에 여러 다른 기전에 의해서도 발생할 수 있는 증상으 로 혈류의 교란이나 이관의 개폐에서도 생길 수 있다. 또 근육 기원 중에도 구개근경련(palatal myoclonus)이나 등골근의 경 련성 수축 등에 의해 나타날 수 있으나, 아직 규명되지 않은 점 이 많다.

이명 발생에 있어 가장 중요한 원인은 청각계에서 일어나는 비정상적인 신경활성 작용으로, 청각 중추에 의한 소리로 오 인되어 인식하는 것이 문제라는 학설이 현재 가장 유력하다.) 이명 발생에 대한 신경생리학적 모델에 의하면 이명을 인지 하는 데에는 청각경로뿐 아니라 대뇌변연계나 자율신경계 같 은 비청각경로의 역할이 크므로 이러한 중추신경계의 포함 정도가 이명의 예후 등에 큰 영향을 미칠 수 있다고 한다. ${ }^{8}$

몸에 물리적 힘을 가함으로써 이명이 생길 수 있고 그 음향 특성에 변화가 올 수 있다는 증거가 최근 축적되고 있다. 측두 하악관절에 압력을 가하거나 움직였을 때 $1 / 3$ 에서 이명의 변 화가 발생하였고, ${ }^{3)}$ 실제 측두하악관절장애와 이명과의 관련 성이 연구되었다.9) 또 경부 통증과 동반되어 일측성 이명이 발 생하거나, ${ }^{10)}$ 편타성 손상(whiplash injury)시 경추와 관련되어 이명이 발생하기도 한다는 보고도 있었다. ${ }^{11)}$

이상의 예들에서 이명의 발생이 체성감각계(somatosensory system)와 연관이 있을 것이라는 이론이 정립되었다. 체성감 각계와 관련된 경로를 보면, 와우신경핵(cochlea nucleus)은 청각계의 첫 중추성핵으로 와우유모세포에서 정보를 받는 데, 그 상층부에서는 섬유띠계(lemniscal system)가 받은 정 보를 일차청각영역(primary cortical auditory area)으로 보내 고 상행로의 섬유띠외부위(extralemniscal portion)는 연합구 역(association area)에 청각정보를 전한다. ${ }^{7)}$ 한편 섬유띠외부 위의 뉴런은 체성감각계 등 다른 감각로에서도 정보를 받으며 쐐기핵(cuneate nucleus)과 널판핵(gracile nucleus)은 배측수 질핵(dorsal medullary nucleus)을 형성해 피부의 고유감각, 촉각, 진동 수용체로부터 정보를 받는다. ${ }^{12)}$ 외측쐐기핵(lateral cuneate nucleus)에는 목, 귀, 후두부 근육에서 오는 구심성섬 유(afferent fiber)가 닿아있어 머리, 귀의 움직임에 대한 정보 를 전한다. ${ }^{12}$

Levine의 체성이명에 대한 신경학적 모델에 의하면 체성 이명은 체성감각-청각의 상호작용으로 중추신경계에서 발생 할 수 있다. 즉 동측수질체성감각핵(ipsilateral medullary somatosensory nuclei)에서 동측의 배측와우신경핵에 이르는 경로가 자극되는 과정에서 동측수질체성감각핵은 외이, 중 이를 자극하는 삼차, 안면, 미주, 설인 신경들의 섬유에서 들어 온 자극들을 동측의 배측와우신경핵 경로로 전달하여 배측 와우신경핵의 탈억제를 일으키게 된다. ${ }^{4)}$ 이 탈억제는 이들 자
극에 의해 억제를 담당하는 신경전달수용체에 하향조절 (down-regulation)이 일어나거나, ${ }^{13)}$ 신경전달물질 방출에 변 화가 생겨서 일어날 수 있다. ${ }^{14}$

삼차신경계와 청각중추 간의 기능적 연결에 있어서 삼차신 경에서의 투사가 중추청각뉴런을 활성화시키는 기전은 최근 에 설명되었는데, ${ }^{15)}$ 즉 삼차신경 뉴런을 자극하면 와우신경 핵과 청각하구(inferior colliculus) 신경핵의 자발적 발화율 (firing rate)이 변해 이것을 환자가 이명의 강도변화로 느끼게 된다. 또 삼차신경 뉴런은 와우신경핵과 청각하구 뉴런의 소 리 반응을 규칙적으로 만들어 이명의 높낮이 변화를 유발한 다. 즉 배측와우신경핵 세포는 삼차신경과 청신경으로부터 입력을 받아 다감각적 통합을 한다. ${ }^{16)}$ 또 배측와우신경핵에 대한 체성감각 입력 중에 이개 관련 근육에서 기원하는 것이 가장 크다는 것이 증명되어 그 관련성이 연구되었다. ${ }^{17}$

본 연구는 이명의 체성 조절(somatic modulation)에 대한 이해를 구하기 위한 기초적 연구로 설정되었다. 연구 대상에서 방음실에 있을 때 자연히 발생하는 이명이 있는 피검사자를 배제하지는 않았다. 왜냐하면 어느 환경에서나 완전히 이명과 유사한 청각적 인지가 없는 경우는 오히려 드물기 때문이다. 정 상인이 무반향실에 들어가면 대부분이 다양한 유사 이명의 발현을 경험하는데, 그 원인은 와우유모세포의 정지전류나 중 이 내 혹은 무반향실 내 공기의 분자 운동일 수도 있으며 코르 티 기관 근처로 흐르는 혈액에서 유래할 수도 있다. ${ }^{18)}$

완전 방음방에서 정상인의 이명이 기록되었고, ${ }^{19)}$ 수초에서 수분에 걸쳐 외부자극 없이 생겼다가 사라지는 이명도 많은 사람들이 경험하지만 문헌상으로는 최근에 거론되기 시작했 다. ${ }^{20)}$ Tucker 등 ${ }^{21)}$ 은 성별과 인종을 분리해 방음방에서 정상 청력인의 자연 이명을 조사한 결과 $64 \%$ 가 이명을 느꼈고 인 종에 따른 차가 있다고 하였다. 본 연구에서 방음실에서의 자 연 이명 발생률은 Heller와 Bergman ${ }^{19)}$ 의 연구 결과보다 낮 게 나왔는데, 이것은 백인과 아프리카계 아메리카인 사이에 서 인종에 따라 이명 발생률이 달랐다는 Tucker의 연구를 상 기시키는 결과다. 이때 이명은 울리는 소리, 높은 소리 순으로 많았는데 이명의 성질에 대한 보다 자세한 설문이 준비되어 야 할 것으로 생각되었다. 방음실에서 5 분 지체 후 이명을 검 사 한 것은 Heller의 예를 따른 것이었다.

일반적으로 근육이 수축되면 그 부분의 체성감각계가 활 성화된다. 본 연구에서 두경부 근육 수축 약 15 초 후에 이명 이 시작되어 30초 정도 지속되는 것으로 관찰되었는데, 수축 이 계속되어도 이명이 더 이상 지속되지 않는다는 사실에 앞 으로 신경학적 해석이 필요하다고 하겠다.

본 연구에서 피험자의 $57.1 \%$ 가 두경부 수축 후 이명을 느꼈 다고 하여 Levine ${ }^{4}$ 의 결과(56\%)와 비슷하였으나, Sanchez 
등 ${ }^{5)}$ 은 $14 \%$ 에서만 이명이 발현되었다고 보고한 것과는 큰 차 이를 보였다. 그들의 연구가 둘 다 어깨, 둔부 등을 포함한 전 신 근육을 대상으로 했으나, 수축 방법에서 Levine은 수동적, Sanchez는 능동적 방법을 사용했으므로 앞으로 이에 관한 검사 신뢰도가 확인되어야 할 것이다.

두경부 수축에 의한 정상인의 이명발현 외에, 이 술식으로 이명 환자에서 기존의 이명이 변화할 수도 있기 때문에, 앞으 로 두경부 근골격에 대한 처치를 통해 특정 이명에 대한 관 리 및 치료를 시행해 볼 수 있을 것으로 생각된다.

본 연구의 문제점은 근육 수축시 그 가해지는 힘이 정량화 되지 않았다는 점이다. 이명의 발생 유무만을 검사할 목적이 었으므로 최대의 힘을 가하는 것으로 설정했는데 앞으로 가 해진 힘에 따른 이명의 발생 여부 및 변화도 검사되어야 할 것이다. 또한 두부 수축에서 자연히 생기는 경부 및 다른 근육 의 수축을 배제할 수 없다는 점도 문제였으며 근 수축시 좌 우측이 있는 경우 우측을 먼저 시행했었는데 앞으로 보다 정밀한 연구가 이루어진다면 턱이나 경부, 후두부 근육의 긴 장도 측정 및 그 조절을 통해 이 계통의 이명 완화에 대한 정 량적 시도가 이루어질 수 있을 것이며 향후 추가 연구시 근 수 축 순서에 대한 고려를 하여야 하겠다. 또 체성감각-청각 상 호작용의 규명에 대한 광범위한 연구가 계속 진행함으로써, 이 명의 원인 규명 및 치료에 있어 개선점을 얻을 수 있을 것으로 본다.

\section{REFERENCES}

1) Marion MS, Cevette MJ. Tinnitus. Mayo Clin Proc 1991;66(6):61420.

2) Anonymous. Definition and classification of tinnitus. Appendix I. In: Evered D, Lawrenson G, editors. Tinnitus. Ciba Foundation Symposium 85. London: Pitman;1981. p.300-2.

3) Rubinstein B. Tinnitus and craniomandibular disorders--is there a link? Swed Dent J Suppl 1993;95:1-46.

4) Levine RA. Somatic (craniocervical) tinnitus and the dorsal cochlear nucleus hypothesis. Am J Otolaryngol 1999;20(6):351-62.

5) Sanchez TG, Guerra GC, Lorenzi MC, Brandão AL, Bento RF. The influence of voluntary muscle contractions upon the onset and modulation of tinnitus. Audiol Neurootol 2002;7(6):370-5.

6) Oosterveld WJ, Kortschot HW, Kingma GG, de Jong HA, Saatci MR. Electronystagmographic findings following cervical whiplash injuries. Acta Otolaryngol 1991;111(2):201-5.

7) Møller AR, Møller MB, Jannetta PJ, Jho HD. Compound action potentials recorded from the exposed eighth nerve in patients with intractable tinnitus. Laryngoscope 1992;102(2):187-97.

8) Jastreboff PJ. Phantom auditory perception (tinnitus): mechanisms of generation and perception. Neurosci Res 1990;8(4):221-54.

9) Chole RA, Parker WS. Tinnitus and vertigo in patients with temporomandibular disorder. Arch Otolaryngol Head Neck Surg 1992;118(8):817-21.

10) Wyant GM. Chronic pain syndromes and their treatment. II. Trigger points. Can Anaesth Soc J 1979;26(3):216-9.

11) Tjell C, Tenenbaum A, Rosenhall U. Auditory function in whiplashassociated disorders. Scand Audiol 1999;28(4):203-9.

12) Thompson AM, Moore KR, Thompson GC. Distribution and origin of serotoninergic afferents to guinea pig cochlear nucleus. J Comp Neurol 1995;351:104-16.

13) Caspary DM, Schatteman TA, Hughes LF. Age-related changes in the inhibitory response properties of dorsal cochlear nucleus output neurons: role of inhibitory inputs. J Neurosci 2005;25(47):10952-9.

14) Potashner SJ, Suneja SK, Benson CG. Regulation of D-aspartate release and uptake in adult brain stem auditory nuclei after unilateral middle ear ossicle removal and cochlear ablation. Exp Neurol 1997; 148(1):222-35.

15) El-Kashlan HK, Shore SE. Effects of trigeminal ganglion stimulation on the central auditory system. Hear Res 2004;189(1-2):25-30.

16) Shore SE. Multisensory integration in the dorsal cochlear nucleus: unit responses to acoustic and trigeminal ganglion stimulation. Eur J Neurosci 2005;21(12):3334-48.

17) Kanold PO, Young ED. Proprioceptive information from the pinna provides somatosensory input to cat dorsal cochlear nucleus. J Neurosci 2001;21(19):7848-58.

18) Paparella: Volume II: Otology and Neuro-Otology Section 3: Diseases of the Ear Part 1: General Problems Chapter 17: Tinnitus William L. Meyerhoff, John C. Cooper. p.1-16.

19) Heller MF, Bergman M. Tinnitus aurium in normally hearing persons. Ann Otol Rhinol Laryngol 1953;62(1):73-83.

20) Dobie RA. Overview: suffering from tinnitus. In: Snow JB, editor. Tinnitus: theory ans Managemant. Hamilton, Ontario: BC Decker; 2004. p.1-7.

21) Tucker DA, Phillips SL, Ruth RA, Clayton WA, Royster E, Todd AD. The effect of silence on tinnitus perception. Otolaryngol Head Neck Surg 2005;132(1):20-4. 